NBER WORKING PAPER SERIES

\title{
HEALTH INSURANCE AND HOUSEHOLDS' PRECAUTIONARY BEHAVIORS - AN UNUSUAL NATURAL EXPERIMENT
}

Shin-Yi Chou

Jin-Tan Liu

James K. Hammitt

Working Paper 9394

http://www.nber.org/papers/w9394

\section{NATIONAL BUREAU OF ECONOMIC RESEARCH 1050 Massachusetts Avenue Cambridge, MA 02138}

December 2002

The views expressed herein are those of the authors and not necessarily those of the National Bureau of Economic Research.

(C) 2002 by Shin-Yi Chou, Jin-Tan Liu, and James K. Hammitt. All rights reserved. Short sections of text not to exceed two paragraphs, may be quoted without explicit permission provided that full credit including, (C) notice, is given to the source. 
Health Insurance and Households' Precautionary Behaviors -

An Unusual Natural Experiment

Shin-Yi Chou, Jin-Tan Liu, and James K. Hammitt

NBER Working Paper No. 9394

December 2002

JEL No. D1, H4, I1

\begin{abstract} insurance may reduce households' motivation to engage in precautionary behaviors such as saving, procurement of private insurance, and spousal labor-force participation. We use the household head's and spouse's joint employment status) to identify the effects of increasing and large effect on household savings and purchase of private accident insurance, but no significant effect on spousal employment.

\author{
Shin-Yi Chou \\ Department of Humanities \\ Jin-Tan Liu \\ Department of Economics \\ and Social Sciences \\ New Jersey Institute of Technology \\ Newark, NJ 07102 \\ and NBER \\ National Taiwan University \\ 21 Hsu-Chow Road \\ Taipei (100), Taiwan \\ and NBER \\ chou@admin.njit.edu \\ liujt@ccms.ntu.edu.tw \\ James K. Hammitt \\ Department of Health Policy \\ and Management \\ Harvard School of Public Health \\ 718 Huntington Avenue \\ Boston, MA 02155-5294 \\ jkh@hsph.harvard.edu
}

By reducing risk of large out-of-pocket medical expenses, comprehensive social health natural experiment provided by the 1995 introduction of National Health Insurance in Taiwan to examine these effects, using pre-existing differences in access to health insurance (tied to the insurance coverage. We find that comprehensive health insurance has a statistically significant 


\section{Introduction}

Over the last century, both developed and developing countries have implemented a wide range of social insurance programs. ${ }^{1}$ The introduction, expansion and reform of these programs raise important questions about the effects of the programs on the behavior of economic agents. One important question is the extent to which these programs crowd out private precautionary behaviors, such as saving, purchasing private insurance, or sending other household members to work.

Understanding the motivations for household precautionary behaviors and the relationship with insurance has important policy implications. If precautionary motives are significant, economic models that ignore them, such as simple life-cycle models, will tend to miscalculate the optimal size of government policy. Hubbard et al. (1995) demonstrated the importance of accounting for precautionary savings to explain the effects of asset-based, means-tested social insurance on patterns in wealth accumulation. In the presence of precautionary motives, government policy may have unintended effects on individuals' welfare. For example, it may increase efficiency by pooling health risks through insurance rather than relying on individuals' precautionary saving, since those who reduce consumption today may not necessarily be ill in the future. ${ }^{2}$

While using theoretical models incorporating precautionary motives to explain economic behaviors when social insurance programs are introduced is appealing, the limited empirical work that is available provides mixed evidence about the strength of precautionary motives. ${ }^{3}$ The difficulty that researchers typically face is that the variation of insurance programs owned by individuals is inevitably correlated with the individuals' unobserved preferences. For example, those who are highly risk-averse are more likely to

\footnotetext{
${ }^{1}$ U.S. examples include social security, unemployment insurance, Medicaid, and Medicare.

${ }^{2}$ For example, Gruber (1997) found strong evidence that unemployment insurance smooths individual consumption. Gertler and Gruber (2001) found that households in developing countries are not able to fully insure their consumption; their results suggest larger welfare gains in terms of consumption smoothing from public subsidies for medical care.
} 
have better health insurance and engage in various precautionary behaviors. Instrumental variables based on arbitrary exclusion restrictions (such as occupation or education) may provide no solution since these variables are likely to be correlated with personal preferences. This paper contributes to this emerging literature by providing empirical evidence on the impact of a significant change in social health insurance on households' precautionary behaviors in Taiwan. Specifically, we will examine the effects of health insurance on households' saving, purchase of accident insurance, and spousal labor supply.

We exploit a unique natural experiment. In March 1995, the Taiwan government inaugurated National Health Insurance to cover health expenses for the entire population. Prior to implementation, there were three major health insurance programs-Government Employee's Insurance, Labor Insurance, and Farmer Health Insurance, which were tied to employment status. Only Government Employee's Insurance provided coverage to the insured's spouse, children and parents. The introduction of the comprehensive NHI coverage had a smaller impact on households where at least one spouse worked in the government sector and could obtain insurance coverage for the entire household before NHI. By comparing changes in behavior between households with no government employees and households with at least one government employee, we are able to identify the impact of NHI. This is a difference-in-differences strategy. ${ }^{4}$ Moreover, we employ a unique data set to exploit the underlying variation in benefits across households within treatment and control groups. Unlike the difference-in-differences method, this strategy allows us to take full advantage of the variation of insurance benefits within households at a point in time and to calculate the elasticity of response to the change in insurance benefits.

\footnotetext{
${ }^{3}$ For example, Guiso et al. (1992) and Dynan (1993) found no support for the precautionary motive, while Skinner (1988), Carroll and Samwick (1998) and Kazarosian (1997) found more support for the precautionary view.

${ }^{4}$ Chou, Liu and Hammitt (forthcoming) use the difference-in-differences method to estimate the impacts of NHI on saving behavior in Taiwan. Their results suggest that the precautionary motive is an important determinant of household saving and consumption behaviors, and that NHI causes a considerable reduction in private saving.
} 
Since insurance benefits could vary because of underlying tastes, the natural experiment described above allows us to use the husband-wife joint employment status as an instrument for insurance benefits and thus to identify the causal relationship between insurance and household's precautionary behaviors. Two factors suggest these instruments are likely to be valid. First, the dramatic expansion of National Health Insurance significantly increased the insurance benefits for households with no government employees. Second, the expansion of NHI is very likely uncorrelated with households' behaviors. As detailed below, although the development of NHI was predicated on concerns about rising health-care costs and access to care, the timing of implementation was determined by political factors unrelated to changes in health-care markets.

Our analyses are based on the Survey of Family Income and Expenditure (SFIE) from 1993 to 1999. This survey contains individuals' labor market status together with detailed information on consumption and saving. The survey also contains information on insurance benefits received by each household.

Our results suggest that households have strong precautionary motives. Therefore, the introduction of comprehensive health insurance significantly reduces households' saving and crowds out private purchase of accident insurance. However, sending other family members to work is not found to be related to the precautionary motives.

The remainder of the paper is organized as follows. Section 2 provides background on health insurance programs in Taiwan and a brief review of the theoretical background and the related empirical literature. Section 3 describes our identification strategy and data. Section 4 discusses the empirical strategy. Section 5 reports the estimation results and Section 6 concludes.

\section{Background}

\section{A. Social Insurance Programs in Taiwan}

National Health Insurance (NHI) was inaugurated in Taiwan in March 1995. NHI dramatically expanded the insured fraction of the population, from 57 percent in 1994 to 92 percent in 1995 and 96 percent in 2000. The timing of the reform was heavily influenced by political factors. In 1984, the Council for Economic Planning and 
Development recommended a national health insurance scheme to be phased-in by the year 2000. In 1986, the Premier declared the objective of "health insurance for all by the year 2000" in his statement to the Legislative Yuan (Congress). However, with the rapid growth of political participation and the growth of the opposing Democratic Progressive Party in the 1980s, in February 1989 the Premier strategically announced the new target year for implementing a national health insurance scheme to be 1995. Foreseeing an election of Legislative Yuan representatives in December 1995 and the first Presidential election in March 1996, the ruling party (Kuomingtung) mobilized its legislators to pass the NHI Law in July 1994. NHI was fully implemented by March 1, 1995, so that the chaos resulting from implementation might vanish prior to the elections. ${ }^{5}$ Thus, although the initiation of universal health insurance was motivated by concerns about health-care expenses, the timing of the policy was driven by politics. Therefore, the implementation of NHI was likely to be uncorrelated with households' economic behaviors.

Prior to implementation of NHI, health insurance was available through three government-sponsored programs - Labor Insurance (LI), Government Employees' Insurance (GEI), and Farmer Health Insurance (FHI). There was virtually no private health insurance, with the exception of supplementary coverage for selected conditions such as cancer or accident. With the exception of GEI, these programs provided very little coverage for family members of the employed individual. As a result, the majority of the uninsured were children under 14 years of age and adults over $65 .^{6}$

The first social insurance program, Labor Insurance (LI), was promulgated in 1950 and initially provided only cash benefits, payable for maternity, injury or sickness, disability, old age, and death. Compensation for inpatient and outpatient medical expenses were added in 1956 and 1970, respectively. ${ }^{7}$ LI was compulsory for five categories of workers between the ages of 15 and $60 .{ }^{8}$ The premium was $6-8$ percent of

${ }^{5}$ Chiang (1997) provides a more detailed description of the reform process.

${ }^{6}$ Peabody et al. (1995) and Cheng and Chiang (1997) provide detailed descriptions of the health insurance programs.

${ }^{7}$ Unemployment benefits were added in 1999.

${ }^{8}$ Those workers included (1) workers employed by mine, a company or firm, a journalistic, cultural, or non-profit cooperative enterprise with more than five employees; (2) employees of government offices or public or private schools who are not legally 
monthly salary, 80 percent of which was paid by the employer and 20 percent by the worker. Since 1995, medical care benefits for ordinary injury or sickness are covered by the National Health Insurance program, while medical costs from occupational injuries are still paid by the Labor Insurance program. Labor Insurance did not offer any benefits to the insured's spouse or other dependents. Self-employed workers (who account for a large share of the Taiwan labor force ${ }^{9}$ ) could obtain Labor Insurance only if they were members of an occupational union.

Government Employees’ Insurance (GEI) was implemented in 1958 and provided benefits including maternity, injury or sickness, disability, old age and death as well as dependents' funeral allowance. Spouses, parents, and children of government employees gained coverage for injury and sickness under Health Insurance for Government Employees’ Dependents Insurance in 1982, 1989 and 1992, respectively. Retired government employees and their dependents became eligible for injury and sickness benefits in 1985. The premium rate was $3-5$ percent of the salary, of which 35 percent was paid by the employee and 65 percent by the government.

Farmers' Health Insurance (FHI) was established in 1985 and implemented in 1989. Under this program, mandatory coverage was provided to members of farmers' associations. Farmers who were above 15 year of age could participate in the program. Insurance benefits included maternity, injury or sickness, disability and death benefits and burial subsidy. Insured members paid 30 percent of the cost, while the government paid 70 percent. The labor insurance and farmer insurance participants received physicians' services through hospitals or clinics that contracted with the programs.

Beginning in 1990, the government also provided health insurance, including maternity benefits and injury and sickness benefits, to low-income households. ${ }^{10}$

entitled to join civil servants' insurance or the insurance of teachers and employees of private schools; (3) workers employed in fishing production; (4) persons receiving vocational training in vocational training institutes registered with the government and (5) members of an occupational union and Fishermen who have no definite employer or who are self-employed.

${ }^{9}$ For example, in 1999, 16 percent of employed persons were self-employed.

${ }^{10}$ The government sets the "monthly minimum expenses" adjusted by the consumer price index and regional variation in income each fiscal year to determine eligibility for lowincome households. For fiscal year 2001, for example, the monthly minimum expenses 
Insurance premiums were paid by the government in full. In 1991, 50.3 percent of the population was covered by health insurance, of which 34.2 percent was covered under Labor Insurance, 5.3 percent under Government Employees' Insurance (with 0.6 percent under Retired Government Employees' Insurance), 7.9 percent under Farmer Health Insurance, and 0.5 percent under Low-Income Households' Health Insurance. ${ }^{11}$

Beginning March 1, 1995, all social insurance-contracted facilities were transferred automatically to hospitals and clinics contracted with the NHI program. By 1996, the Bureau of National Health Insurance contracted with 97 percent of the hospitals and 90 percent of the clinics. The NHI provides uniform comprehensive benefits, and is financed by payroll taxes and general revenues. By law, all citizens are required to participate in NHI. Insurance coverage is similar to the original social programs with some expansion for severe illnesses and home health care.

The principal source of finance is a payroll tax. The government share of the premium varies among the insured groups. For government employees and their dependents, the insurer and the government pay 40 percent and 60 percent of the premium, respectively. For private employees and their dependents, the insured and the employer pay 30 percent and 60 percent of the premium, and the government covers the remaining 10 percent. For the self-employed and their dependents, and for persons who do not fit into any working group, the insured pays 60 percent and the government pays 40 percent. For farmers and dependents, the insured pays 30 percent and the government 70 percent. For low income families, the government pays the entire premium (Chiang, 1997).

\section{B. Theoretical Background and Previous Studies}

Households can insure against or adapt to future economic downturns in a variety of ways, including precautionary saving, purchasing commercial life and accident insurance, sending children or spouses to work, or moving in with extended family when

are US\$337 in Taipei City, US\$265 in Kaohsiung City, and US\$220 in Taiwan Province. Families whose average monthly income is below this amount are classified as lowincome. In 2000, only 0.6 percent of the population was considered members of lowincome families (http://www.gio.gov.tw/taiwan-website/5-gp/yearbook). 
adversity occurs. With the availability of comprehensive health insurance to reduce unexpected medical expenditures, households may face less financial risk and may respond by reducing their precautionary behaviors.

Implementation of National Health Insurance might affect households' saving decisions through two pathways: a precautionary motive and an income (or redistribution) effect. By reducing uncertainty about the magnitude of future out-ofpocket health expenditures, comprehensive health insurance can substantially reduce the demand for precautionary saving. If it reduces a household's expected medical expenses (net of premiums and taxes to cover the program), NHI may also increase disposable income, and thus increase household saving.

Several studies provide evidence of a negative correlation between social health insurance and saving or wealth holdings. Using simulation, Kotlikoff (1989) showed that saving is smallest when public health insurance is available and largest when individuals have to self-insure against unexpected health expenditures. Kantor and Fishback (1996) found that the introduction of workers' compensation reduces private saving by approximately 25 percent. Engen and Gruber (2001) also showed that unemployment insurance leads to a significant reduction in asset accumulation. Only Starr-McCluer (1996) found a positive effect of health-insurance coverage on wealth holdings, even after controlling for the potential selection effect.

Intuitively, households without access to comprehensive health insurance have a stronger incentive to purchase other forms of insurance that will reduce their exposure to financial risk, such as accident insurance. ${ }^{12}$ Thus, the implementation of NHI, by reducing the risk of future medical expenditures, may crowd out private purchase of accident insurance. In other contexts, Kantor and Fishback (1996) found that the presence of workers' compensation at least partially crowds out private accident insurance, and Cutler and Gruber (1996) suggested that the increase in Medicaid coverage was associated with a reduction in private insurance coverage. Alternatively, the introduction

${ }^{11}$ Military personnel (2.4 percent of the population in 1991) receive health coverage from National Defense hospitals. 
of NHI may increase the private purchase of supplemental insurance by promoting health knowledge in the general public or by improving information flow in the market. ${ }^{13}$

Another potential response to the absence of health insurance is to increase labor supply by other family members. ${ }^{14}$ As the labor supply of secondary earners is usually more elastic to household income, the introduction of NHI, by increasing the insurance benefits which are independent of employment status, may affect spousal labor supply. Chou and Staiger (2000) found that the availability of social health insurance reduced spousal labor force participation in Taiwan, and other studies have found that the availability of spousal health insurance leads married women to work fewer hours (Olson, 1998; Buchmueller and Valletta, 1999). Similarly, Cullen and Gruber (2000) found that unemployment insurance reduces spousal labor supply.

\section{Identification Strategy and Data}

\section{A. Identification Strategy}

Our estimation strategy compares the changes in household precautionary behaviors associated with the introduction of NHI between two types of households: those covered by GEI, who experienced virtually no difference in insurance coverage before and after NHI, and those covered by other programs, who experienced an expansion of coverage for household members. Before NHI, if at least one spouse worked in the government sector, the other spouse, children, and parents could be covered under the extended insurance program. We use households with at least one government-employed spouse as our control group (Group G).

Based on the variations in insurance benefits available to households before NHI, we divide households with no government employees ("non-government employed

\footnotetext{
${ }^{12}$ The effects of the magnitude of one financial risk on an individual's willingness to incur other risks are complex, and have been investigated by Pratt and Zeckhauser (1987), Kimball (1993), and Gollier and Pratt (1996), among others.

${ }^{13}$ For example, Gertler et. al. (1994) found that information limitations reduce the demand for supplement Medical insurance.

${ }^{14}$ Gruber and Madrian (2002) surveyed the literature and found that health insurance appears to be an important factor in the labor supply decision of married women.
} 
households") into five treatment groups according to their current employment status. ${ }^{15}$ Households in the treatment groups received less generous benefits before NHI, and so the introduction of NHI should have had more significant impacts on these households' precautionary behaviors. Group PP consists of households where both household head and spouse work in the private sector. These households could obtain Labor Insurance for the head and spouse, but not for dependents. Group PN includes households where only the head works in the private sector and the spouse is either not in the labor force or unemployed. Similar to Group PP, the household head was covered under Labor Insurance, but benefits were not extended to other family members. Group F is agricultural households. These households were covered under Farmer's Health Insurance, which provides benefits only to household members who farm (e.g., children under age 14 were not covered). Group NN consists of non-employed households. This group is a mixture including retired, low-income households, and other non-employed households. Retired government employees could obtain health insurance for themselves and their spouse, but not for other dependents. Low-income households were also covered by insurance. Other non-employed households would not have access to health insurance, unless their children or parents had Government Employees' Insurance. Finally, Group PS includes households where both the head and spouse are selfemployed, or one is self-employed and another does not work. Self-employed workers could obtain Labor Insurance only if they are members of an occupational union. Table 1 summarizes our control and treatment groups and their insurance coverage before NHI.

\section{B. Data and Sample}

Our data are from the Survey of Family Income and Expenditure (SFIE), conducted each year since 1976 by the Directorate-General of Budget, Accounting and Statistics, Taiwan. These data have been used by other researchers (e.g. Deaton and Paxson, 1994a; 1994b; Chou and Staiger, 2001). New samples are drawn each year, so we cannot track households longitudinally. About 13,000 to 16,000 households are surveyed and approximately 52,000 to 68,000 civilians aged 15 and above are

${ }^{15}$ As described below, households are sampled independently each year and we are unable to track households over time. 
interviewed each year from 1993 to 1999 . The survey contains information on demographic characteristics, economic status, and industrial sector of employment of each member of the sampled households. It also includes information on household income and consumption. Household income includes salaries, entrepreneurial, property, and transfer income for all household members. Total consumption expenditures include both durable and nondurable goods. For the household head and spouse, the survey provides information on individual wage rates and incomes.

Our observation unit is the household, since the consumption expenditures and some income measures are collected only at the household level. Our sample is restricted to households headed by a 20 to 65 year old married person. The final sample consists of 64,967 households, of which 6,662 (10.3 percent) are in the control group (Group G), 11,819 (18.2 percent) are in Group PP, 24,193 (37.2 percent) are in Group PN, 7,068 (10.9 percent) are in Group F, 6,223 (9.6 percent) are in Group NN, and 9,002 (13.9 percent) are in Group PS.

When estimating spousal labor supply, we restrict attention to households where the head is employed. The analysis sample contains 50,423 households, of which 6,507 household heads work in the government sector and 43,916 household heads work in private sector.

Descriptive statistics are presented in Table 2. The control group (G) has the highest average household income (NT\$1,023,000), followed by groups PP, PN, PS, NN and F. Half of the NN households are headed by a female, while the proportion for the other groups is less than one quarter. Households in groups $\mathrm{F}$ and NN have older heads, fewer children younger than 18 years old, and more children older than 18. Reflecting the distribution of population and agriculture in Taiwan, 77 percent of group F resides in the middle or south of the island, while more than 45 percent of the other groups reside in the north. Education levels are significantly higher in the control group.

\section{Insurance Benefits for Medical Care}

A key feature of the SFIE is the inclusion of insurance benefits under various social insurance programs. Insurance payments are available in the survey from 1993 to 1999. To distinguish the type of social insurance program available to the households, we rely on the household head's and spouse's employment status. As described in the 
previous section, after 1995, medical care benefits are offered by NHI but GEI, LI and FHI continue to provide other non-medical care benefits. The SFIE includes information on payments from all four insurance programs. Since our interest is the impact of medical care insurance on precautionary behaviors, only the medical-care insurance benefits are used in the analysis.

Each year, the survey imputes injury and sickness benefits for households based on the household's age composition and unreleased information on number of physician visits and number of hospitalizations. ${ }^{16}$ Average health care insurance benefits covered under GEI, LI, and FHI were NT\$19,870 and NT\$24,039 in 1993 and 1994, respectively, and under NHI were NT\$37,969, NT\$39,495, NT\$42,736, and NT\$45,242 in 1996, 1997, 1998 and 1999, respectively.

Table 3 presents time trends and statistics of health insurance benefits across control and treatment groups. Agricultural families (Group F) (who are much older on average) received the highest health insurance benefits (NT\$26,890) before NHI, followed by Groups G and PP. Self-employed households (Group PS) received the smallest benefits (NT\$14,194) and Group NN received the second smallest (NT\$19,745). Roughly 23 percent of households in Groups NN and PS received no benefits. After NHI, health insurance benefits increased for all households. The largest increases were to nonemployed households (NN) (NT\$25,091), followed by Group PS (NT\$18,199) and Group F (NT\$17,409). Insurance benefits increased by only NT\$2,999 for the control group G.

\section{Empirical Strategy}

\section{A. Difference-in-Differences Estimation}

The 1995 introduction of NHI allows us to exploit the variation with respect to prior health insurance programs to identify the impact of NHI on households' precautionary behaviors. The most straightforward approach is to use the difference-in-

\footnotetext{
${ }^{16}$ Medical care utilization information is available in the data only after NHI. The information on medical care insurance benefits for each respondent before NHI were obtained through personal communications with staff at the Directorate-General of Budget, Accounting and Statistics, Taiwan in November 2001.
} 
differences (DD) framework. The behavior changes of the control group are assumed to capture any systematic factors, while the changes in the treatment groups reflect both the same systematic factors and the impact of the policy intervention. By comparing the changes of treatment and control groups, we seek to identify the effect of NHI. We omit the transition year 1995 and pool the control and treatment groups for $1993-1994$ and $1996-1999$ to estimate the probit equation:

$P\left(Y_{i j t}\right)=\Phi\left(\beta_{0}+\beta_{1} X_{i j t}+\sum_{k=1}^{5} \beta_{2 k} T_{i j t k}+\beta_{3} N H I_{i j t}+\sum_{k=1}^{5} \beta_{4 k}\left(T_{i j t k} \times N H I_{i j t}\right)+\beta_{5} \delta_{j}+\beta_{6} \tau_{t}+\varepsilon_{i j t}\right)$

where $i$ indexes household, $j$ indexes geographic region and $t$ indexes year. $Y$ is the dependent variable, detailed below. $X$ is a vector of observable characteristics, $\delta$ is a fixed regional effect and $\tau$ is a fixed year effect. $N H I$ is an indicator for whether the year is after the policy change (1995), and $T_{k}$ is a dummy indicating whether the household belongs to treatment group $k$. Each coefficient $\beta_{4 k}$ can be interpreted as an estimate of the impact of the program on a given treatment group.

We consider three binary dependent variables indicating whether the household (1) had positive savings, (2) purchased accident insurance, and (3) included an employed spouse. We also evaluate the effect of NHI on the magnitude of household savings, using an analogous OLS regression (including households with zero savings). Household savings is defined as the difference between total household disposable income and household consumption expenditures. The all-item Consumer Price Index (CPI) is used to convert all money figures to 1991 NT dollars. ${ }^{17}$ As shown in Table 4, before NHI, 91.0 percent of the control group had positive savings, in contrast to only 78.5 percent of the $\mathrm{NN}$ group. After NHI, the fraction having positive savings remained almost the same in the control group, but decreased for all the treatment groups. The control group (G) and group PP increased savings after NHI, possibly due to economic growth during the period. In contrast, groups F, NN and PS decreased their savings after the policy change.

The survey asked households the amount paid for accident insurance premiums. We used this information to create a dummy variable with value one if the household purchased accident insurance and zero otherwise. In the control group, 64.2 percent

${ }^{17}$ The average exchange rate was US\$1=25.75 New Taiwan dollars (NT\$) in 1991. 
purchased accident insurance before NHI, while the fraction of treatment group households purchasing accident insurance ranged between 49.7 percent (Group F) and 76.5 percent (Group PP) (see Table 4). After NHI, the percentage of households purchasing accident insurance increased for all groups. The increase was much larger for the control group (18.7 percent) than for the treatment groups (1.7 percent to 4.3 percent).

Spousal labor force participation is defined as a binary variable which is equal to one if the spouse works as an employer, employee or self-employed worker in the public or private sector. ${ }^{18}$ As show in Table 5, the spousal labor force participation rate of government households remained the same (63.1 percent) after the NHI reform, while the rate increased from 42.8 percent to 44.9 percent for the non-government households.

The variable $X$ in Eq. (1) is a vector of demographic and economic characteristics of the household to control for any observable differences between households that might confound the analysis: household disposal income, household head's education, gender, age and age squared, spousal education, number of children under age 18, number of children over age 18, and number of elderly parents or grandparents. Education is measured by five dummy variables for completion of middle school $(9$ years of education), high school (12 years of education), community college (15 years of education), university (16 years of education), and graduate school (18 years of education).

The difference-in-differences approach requires several identifying assumptions. First, there should be no contemporaneous shocks (other than the NHI program) that might differentially affect precautionary behaviors of the treatment and control groups. Second, there should be no differences in the underlying trends in savings, private purchase of accident insurance, or spousal labor supply between the control and treatment groups. We discuss the extent to which violations of these assumptions may affect our results in more detail below.

One disadvantage of a difference-in-differences strategy is that it does not fully account for the variation in insurance benefits within the group. In the next subsection, we describe an improvement to the difference-in-differences approach that exploits the

${ }^{18}$ We do not include non-paid household workers as labor force participants. 
variations in insurance benefits. This approach is similar to the method used by Gruber (2000).

\section{B. Parameterized Model and Two-Stage Least Squares Estimation}

Since the survey reports insurance benefits before and after NHI, we are able to estimate the following regression:

$$
P\left(Y_{i j t}\right)=\Phi\left(\beta_{0}+\beta_{1} X_{i j t}+\sum_{k=1}^{5} \beta_{2 k} T_{i j t k}+\beta_{3} N H I_{i j t}+\beta_{4} B_{i j t}+\beta_{5} \delta_{j}+\beta_{6} \tau_{t}+\varepsilon_{i j t}\right)
$$

where $B$ represents insurance benefits for medical care and the other variables are as defined in equation (1). The coefficient $\beta_{4}$ estimates the impact of an additional dollar of insurance benefits on household precautionary behaviors. Although the amount of benefits are not known to the household ex ante, the amount of benefits may serve as an indicator of expected benefits, since households have much more information about their likely medical expenses than is available through the survey.

The estimated coefficient $\beta_{4}$ could be biased and inconsistent if there are omitted variables which are correlated with both insurance benefits and precautionary behaviors. For example, we do not have good measures for health. Households with poor health may receive higher insurance benefits because of more frequent or intensive treatment, and could also take more precautions to prevent future adverse events. In this case, we may underestimate the impact of insurance benefits. On the other hand, if households with poor health (who receive larger insurance benefits) are less able to self-insure against future economic downturns, then we may overestimate the impact of insurance benefits.

To resolve the problem of omitted variables, we estimate equation (2) using twostage least squares. The natural experiment provides a source of instrumental variables. After controlling for fixed effects for the five treatment groups $\left(T_{k}\right)$, policy change $(N H I)$, region $(\delta)$ and time $(\tau)$, the model can be identified by the variations in insurance coverage changes after NHI in the treatment groups relative to the control group $\left(T_{k}\right.$ $\times N H I, k=1,2,3,4,5)$.

The first stage results show that the NHI program significantly increased the insurance benefits received by households in the treatment groups. These results are of 
intrinsic interest because they suggest a redistributive effect of NHI toward lower income groups. The increases in benefits were the largest for group NN (NT\$23,064), followed by groups PS (NT\$16,143), F (NT\$14,837), PN (NT\$10,468) and PP (NT\$2,165). These coefficients are statistically significant at the 1 percent level (except that for PP at 10 percent level). The F-test of joint significance of the five interaction terms is 107.39, which is significant at the 1 percent level. The partial $R^{2}$ of the excluded instruments from the first-stage regression is 0.043 , which compares favorably with those reported by Bound, Jaeger, and Baker (1995). Weak instruments can cause an IV estimator to have a large asymptotic bias, but these results suggest that our instrumental variables have substantial explanatory power regarding insurance benefits.

\section{Empirical Results}

\section{A. Results on Savings}

The effects of NHI on the probability and magnitude of household savings are reported in Table 6 . We find a negative and highly significant effect of NHI on both outcomes. The probit estimates imply that NHI reduced the odds of having positive savings by 7.0 percent for group PS, and by 4.0 percent, 3.4 percent, 2.6 percent and 1.3 percent for groups NN, PN, PP and F, respectively. The OLS estimates imply that NHI reduced average savings by roughly NT $\$ 25,100$ for group PS, and by NT $\$ 24,100$, NT\$22,800, NT\$20,400, and NT\$15,500 for groups F, NN, PN, and PP, respectively. These findings suggest that the NHI program has a sizable effect on savings behavior, which is consistent with a precautionary savings response to reductions in the risk of medical-care expenditures.

We also evaluate the marginal effect of the change in insurance benefits on household savings. As discussed above, insurance benefits could be endogenous due to omitted health variables. We report both probit/OLS and probit IV/ 2SLS results in Table 7. The results are similar to those of the difference-in-differences approach: household saving is significantly and negatively related to insurance benefits. The probit estimates suggest that the probability of positive savings falls 7.2 percent for each NT $\$ 100,000$ of insurance benefits. The OLS estimates suggest that savings fall by NT $\$ 0.41$ for each NT\$1 increase in insurance benefits. The estimated average elasticity is -0.055 . 
The two-stage least square estimates suggest stronger effects of insurance benefits. Using the probit IV estimates, we find that the probability of positive savings decreases by 13.7 percent for each NT\$100,000 of insurance benefits, and that savings fall by NT $\$ 0.84$ for each NT\$1 increase in insurance benefits (an average elasticity of 0.113). Kantor and Fishback (1996) used a U.S. household survey for 1917-1919 and found the introduction of workers' compensation in the 1910s significantly reduced workers' saving. Each dollar increase in expected benefits was associated with a reduction in saving of $\$ 0.56$ to $\$ 2.24$. Gruber and Yelowitz (1999) found that the Medicaid program lowers asset holdings by 38 to 43 cents for each dollar of Medicaid eligibility. Over the 1984-1993 period, the Medicaid expansion lowered wealth holding by an estimated 18 percent.

We test the validity of our exclusion restrictions using the test statistics $N R^{2}$ from regressing the IV regression residuals on the instruments (treatment group dummies and NHI dummy interactions) and exogenous variables, where $N$ is the sample size and $R^{2}$ is the goodness-of-fit statistic (Staiger and Stock, 1997). The test statistics $\left(\chi^{2}=7.59\right)$ does not suggest violation of the overidentification restrictions. This test, together with the results from the first stage regression, suggests that our instruments are legitimate.

We can use OLS and 2SLS estimates to measure the net effect of the National Health Insurance program. The average increases in insurance benefits after NHI are reported in Table 3. Using the probit estimates, the estimated reductions in the odds of having positive savings are 1.8 percent, 1.3 percent, 1.3 percent, 0.9 percent and 0.3 percent for groups NN, PS, F, PN, and PP, respectively. Results based on the IV probit estimates are larger, 3.4 percent, 2.4 percent, 2.4 percent, 1.7 percent and 0.6 percent for groups NN, PS, F, PN, and PP, respectively. We also find that NHI reduces savings by between NT\$1,776 (PP) and NT\$10,161 (NN) based on the OLS estimates, and between NT\$3,671 (PP) and NT\$21,001 (NN) based on the 2SLS estimates.

\section{B. Results on Private Purchase of Accident Insurance}

Table 8 reports the estimated effect of NHI on private purchase of accident insurance. The difference-in-differences estimates suggest that NHI significantly reduces the purchase of supplementary accident insurance. The estimated decreases are 26.7 
percent, 20.8 percent, 20.7 percent, 19.4 percent and 17.6 percent for groups NN, F, PS, $\mathrm{PN}$, and PP, respectively.

When considering insurance benefits directly, probit estimates suggest that the probability of purchasing private accident insurance decreases by 4.2 percent for each NT\$100,000 increase in insurance benefits. The IV probit estimates suggest a significantly larger effect: the estimated probability of purchasing private accident insurance falls by 63 percent for each NT $\$ 100,000$ increase in insurance benefits.

We can estimate the total effect of NHI on purchase of private accident insurance. Following the same procedure as for savings above, the OLS estimates imply that NHI reduced private purchase of accident insurance by 1.1 percent, 0.73 percent, 0.76 percent, 0.53 percent and 0.18 percent for groups NN, F, PS, PN and PP, respectively. The IV probit estimates imply the reductions were 15.8 percent, 10.9 percent, 11.4 percent, 7.9 percent, and 2.8 percent for groups NN, F, PS, PN and PP, respectively. These results are consistent with the Kantor and Fishback (1996) study of workplace-accident compensation in the 1910s and the Cutler and Gruber (1995) study of the Medicaid program, which also found that social insurance programs crowd out the purchase of private insurance.

\section{Results on Spousal Labor Supply}

The introduction of NHI could also reduce spousal labor supply as one kind of self-insurance. In contrast to Chou and Staiger (2001), our results reported in Table 9 do not suggest any significant impact of NHI on spousal labor force participation. One significant difference between the two studies is that we examine effects over a longer time period. The Chou and Staiger result may represent a short-run effect, while we estimate a longer run effect which is not statistically significant. Our results suggest that the precautionary motive for secondary earners' to work is very weak. Gruber and Madrian (2002) concluded from a review of the literature that health insurance is important for the labor supply decisions of married women. However, all the studies they review assume that the husband's health insurance is exogenous to the wife's labor force participation, a debatable identification strategy. 


\section{Comparisons between Estimates from DD, OLS and $2 S L S$}

Compared with OLS, the two-stage least squares estimates suggest a larger effect of NHI on households' behaviors (see Tables 7 and 8). One explanation is that our instrumental variables provide an estimate for specific groups (PP, PS, F and NN) affected by the policies. If these non-government-employed households have higher-thanaverage marginal responses to insurance benefits, then two-stage least squares estimates based on the husband-wife joint employment status might yield larger estimates of the response of increased insurance benefits than the corresponding OLS estimates. ${ }^{19}$ The underlying heterogeneous responses to policy point to the weakness of difference-indifferences and two-stage least squares estimates in that their results may not be generalized beyond the treatment groups in the study (Meyer, 1995).

\section{E. Alternative Explanations}

The identification strategy used above requires several assumptions. In this subsection, we consider possible alternative explanations for our findings. If we fail to find strong evidence for the other possibilities, we will be more confident of our conclusion that NHI has a significant impact on households' precautionary behaviors.

If long-run trends in households' precautionary behaviors differ between control and treatment groups, then we may risk interpreting preexisting trends as treatment effects. We test for this underlying trend by re-estimating the models on data from 1991 to 1994 . We construct a new sample of households headed by a 20 to 65 year old married person with the data from 1991 and 1992 as the "before" period and 1993 and 1994 as the "after." Most of the major reforms in government health insurance policies were implemented before 1990, and there were no major changes around 1993. We estimate the difference-in-differences model on those data. Negative and significant coefficient estimates imply that there was a preexisting trend.

${ }^{19}$ A similar argument has been made by Card (1999) to explain the large gap between 2SLS and OLS estimates on returns to education. The fact that the instrumental variables, and thus the 2SLS estimates, are affected by the underlying heterogeneity in response to the policy is discussed by Imbens and Angrist (1994) and emphasized by Angrist and Krueger (2001). 
The estimated effects on savings (not reported in the table) of this new exercise are smaller than the corresponding estimates in Table 6 , and not significantly different from zero. ${ }^{20}$ They are NT\$-9,579 for group PP, and NT\$8,755, NT\$8,065, NT\$21,701, and NT\$11,321 for groups PS, PN, NN and F, respectively. None are statistically significant. These results suggest that there was no between-group difference in savings trends before the NHI reform; the differential between the control and treatment groups arises after the 1995 reform.

Another alternative explanation for our findings is that some change in the economic environment other than NHI occurred and affected households in the control and treatment groups differently. One potential candidate is the business cycle. Between 1994 and 1996 the economic growth rate in Taiwan fell by 1 percent, from 7.1 to 6.1 percent. Since economic downturns will affect households' saving and labor supply decisions, our treatment effects may be contaminated by economic fluctuations.

To control for possible business-cycle effects, we include county unemployment rates in the models. Some of the coefficients on insurance benefits become slightly smaller but are all still significant. For example, IV estimates imply that the probability of positive savings falls by 12.9 percent for each NT $\$ 100,000$ increase in insurance benefits and that savings fall by NT $\$ 0.75$ for each NT\$1 increase in insurance benefits. These results suggest that control and treatment groups did not respond to economic fluctuations differently and that our estimates of treatment effects may be attributed to the NHI reform.

\section{Conclusion}

Using the dramatic expansion of health insurance programs for various groups in Taiwan as instruments for changes in insurance benefits, we estimate the effect of social health insurance on households' precautionary behaviors. Using coefficients from difference-in-differences, OLS and 2SLS model specifications, we estimate that the introduction of National Health Insurance decreased households' savings by 5-15 percent

\footnotetext{
${ }^{20}$ We also estimated the difference-in-differences model on spousal labor supply. Again, the coefficient $(0.01)$ is not significant $(\mathrm{t}=0.82)$. We do not have data on purchase of accident insurance before 1993.
} 
using difference-in-differences coefficients, 0.6-7.0 percent using OLS coefficients, and 1.3-13.8 percent using 2SLS coefficients. These results are consistent with recent studies that have found that coverage by other social programs, such as disability insurance (Kantor and Fishback, 1996), unemployment insurance (Engen and Gruber, 2001) and Medicaid (Gruber and Yelowitz, 2000), are negatively associated with savings. While there are a number of potential explanations for our results, we find the impact of the introduction of National Health Insurance to be the most compelling explanation.

Social health insurance may also have an impact on other precautionary behaviors. Our evidence suggests that the introduction of National Health Insurance significantly reduced households' purchase of private accident insurance. The estimated effects are sizeable: 17.6-26.7 percent (DD) and 2.8-15.8 percent (2SLS).

Applying similar empirical specification to spousal labor supply yields no evidence that the expansion of the NHI decreased labor force participation of secondary earners. These results suggest that precautionary motives are not among the most important reasons for sending other household members to work in Taiwan.

Our study offers empirical support for the proposition that, by reducing uncertainty about future medical expenses, the introduction of large-scale social health insurance can substantially reduce households' precautionary behaviors. However, the welfare implication of the behavioral change is not clear. On one hand, the reduction of household savings could improve welfare by increasing current consumption. If the household increases educational expenditures, for example, the long run impact could be beneficial to society. If the labor force participation of the secondary earners decreased, and therefore increased the time invested in child development, the consequences could also be favorable. However, high national saving, as well as high labor force participation, are important contributors to a nation's economic growth. How to balance these conflicting objectives and how social health insurance affects welfare over time remain unanswered. While this study provides useful data, more research is required to assess the welfare implications and to provide more accurate guidance for policy reform. 


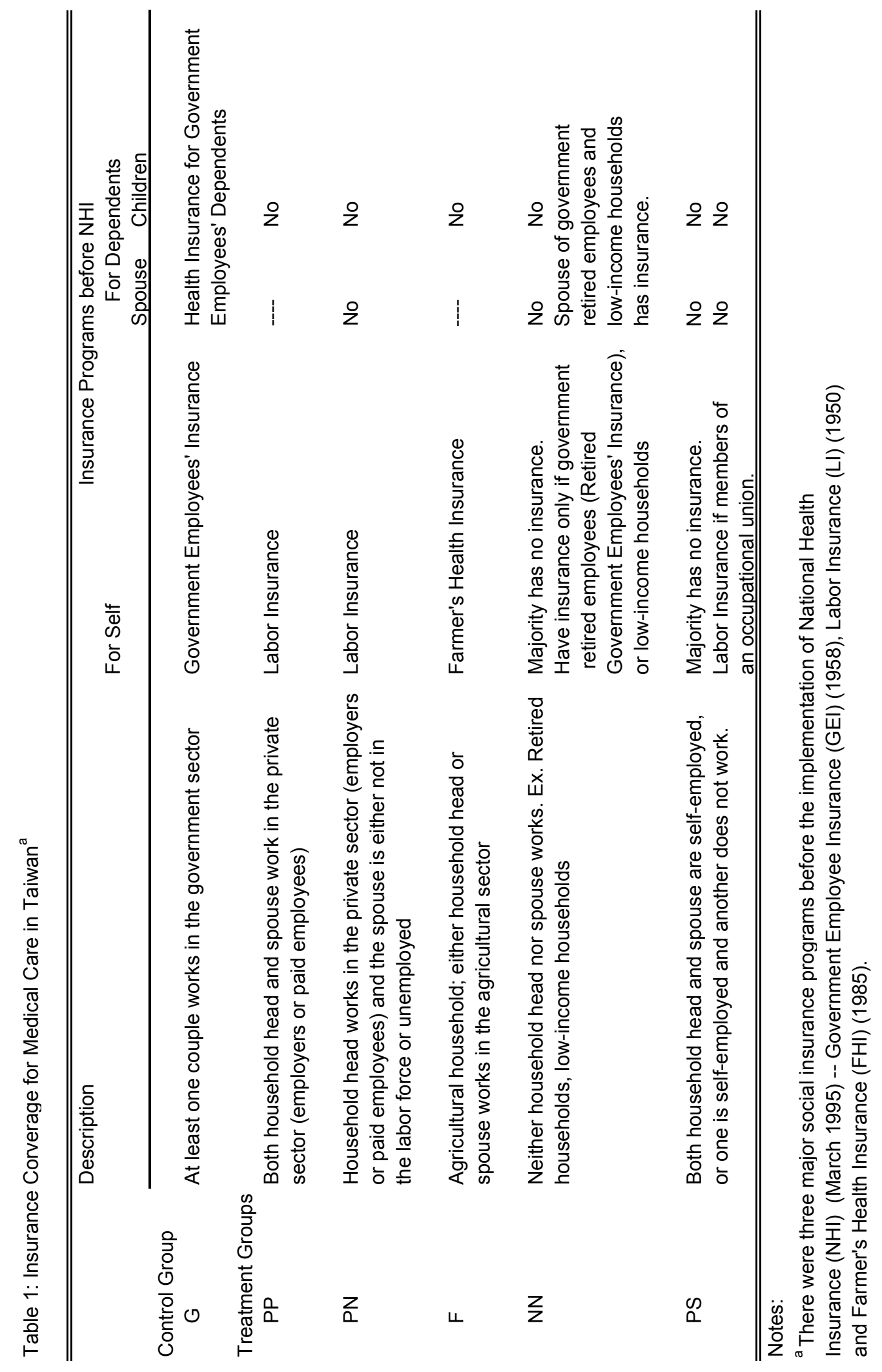




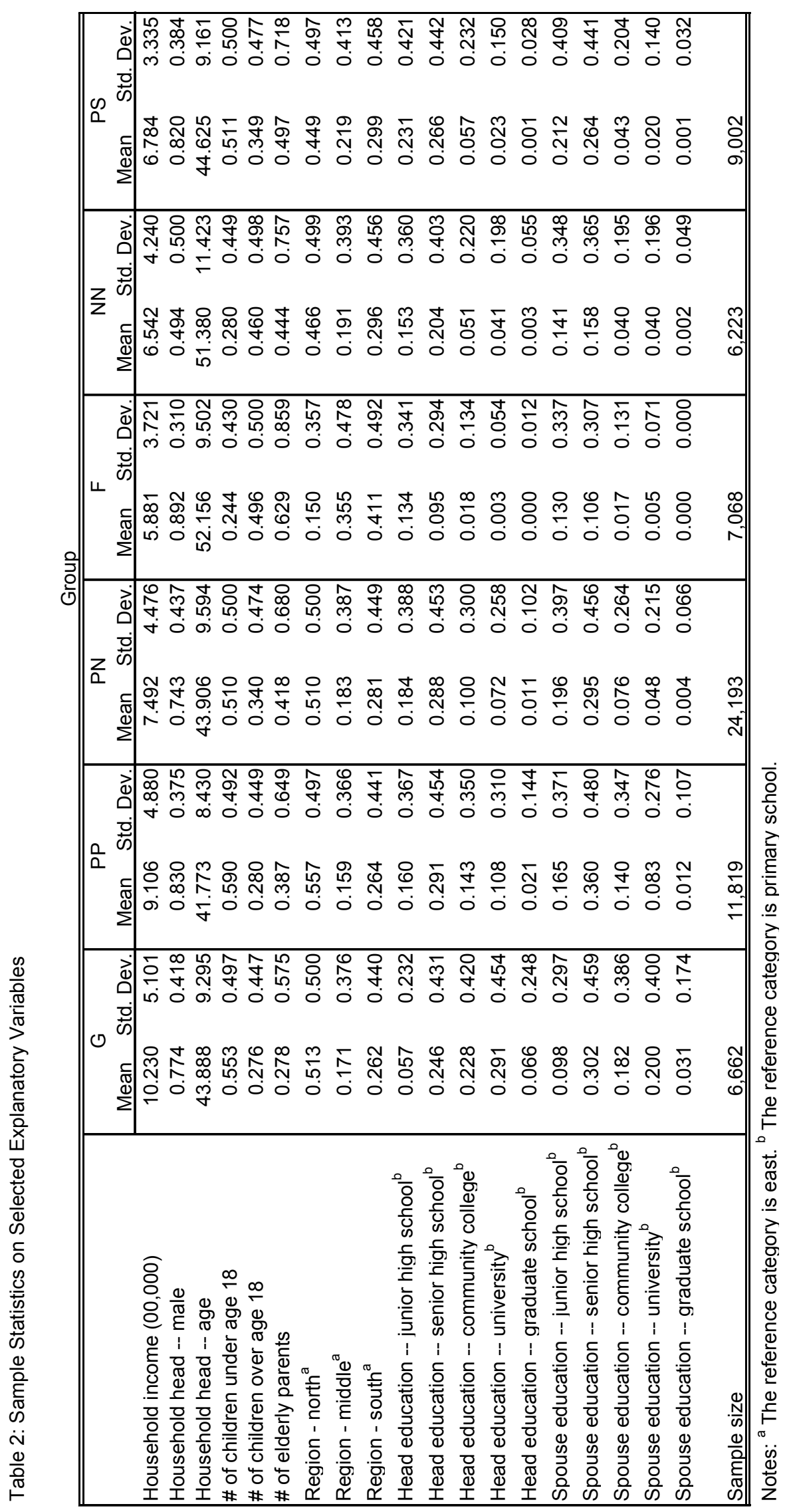




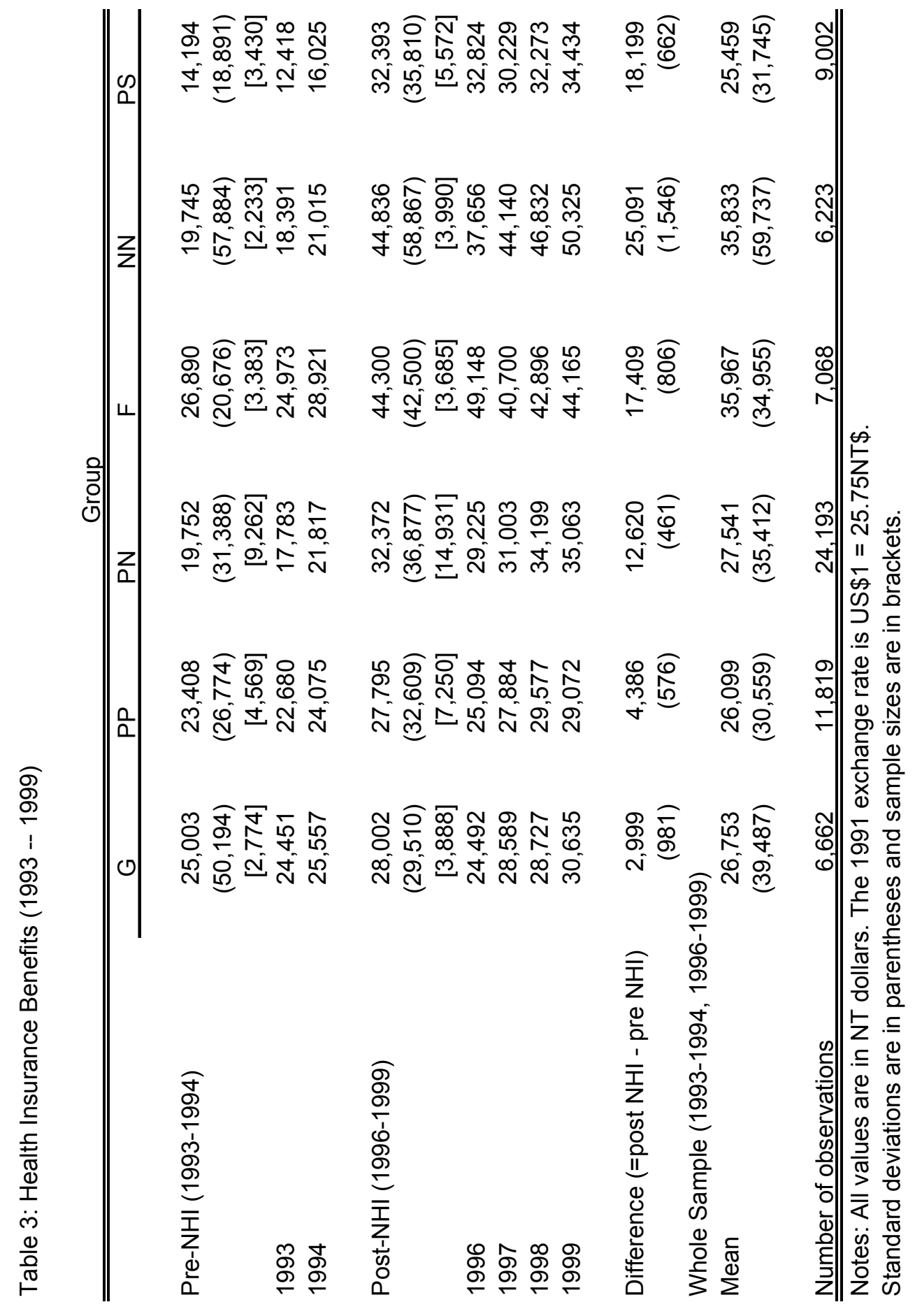




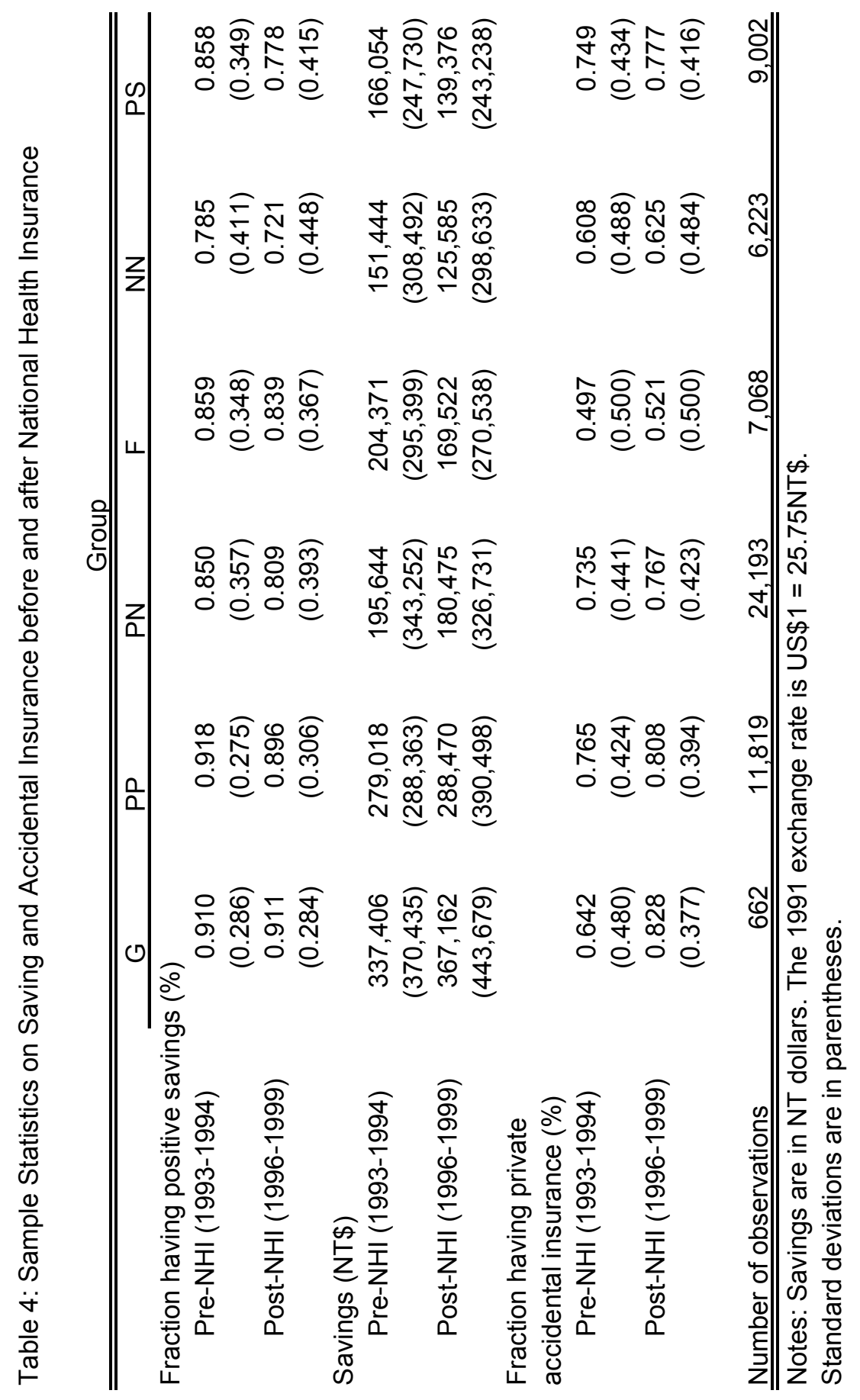


Table 5: Sample Statistics on Spousal Labor Supply before and after National Health Insurance

\begin{tabular}{|c|c|c|}
\hline & $\begin{array}{l}\text { Control Group } \\
\text { Household head is } \\
\text { in government sector }\end{array}$ & $\begin{array}{l}\text { Treatment Group } \\
\text { Household head is } \\
\text { in private sector }\end{array}$ \\
\hline \multicolumn{3}{|c|}{ Spousal Labor Force Participation } \\
\hline \multirow[t]{3}{*}{ Pre-NHI (1993-1994) } & 0.631 & 0.428 \\
\hline & $(0.483)$ & $(0.495)$ \\
\hline & {$[2,701]$} & {$[16,894]$} \\
\hline \multirow{3}{*}{ Post-NHI (1996-1999) } & 0.631 & 0.449 \\
\hline & $(0.482)$ & $(0.497)$ \\
\hline & {$[3,806]$} & {$[27,022]$} \\
\hline
\end{tabular}

Notes:

Standard deviations are in parentheses and sample sizes are in brackets. 
Table 6: Difference-in-Differences Estimates of the Impact of National Health Insurance on Saving

\begin{tabular}{|c|c|c|c|c|c|}
\hline \multirow[b]{3}{*}{$\mathrm{NHI}$ (post 1995)*PP } & \multicolumn{3}{|c|}{$\begin{array}{c}\text { Saving }>0 \\
\text { Probit }\end{array}$} & \multicolumn{2}{|c|}{$\begin{array}{c}\text { Saving }(00,000) \\
\text { OLS }\end{array}$} \\
\hline & Coeff. & Std. Err. & M.E. & Coeff. & Std. Err. \\
\hline & $-0.124^{b}$ & $(0.060)$ & -0.026 & $-0.155^{b}$ & $(0.060)$ \\
\hline $\mathrm{NHI}$ (post 1995)* & $-0.162^{a}$ & $(0.052)$ & -0.034 & $-0.204^{a}$ & $(0.053)$ \\
\hline $\mathrm{NHI}($ post 1995)* $\mathrm{F}$ & -0.062 & $(0.061)$ & -0.013 & $-0.241^{a}$ & $(0.057)$ \\
\hline $\mathrm{NHI}$ (post 1995)*NN & $-0.185^{a}$ & $(0.061)$ & -0.040 & $-0.228^{a}$ & $(0.063)$ \\
\hline $\mathrm{NHI}$ (post 1995)*PS & $-0.307^{a}$ & $(0.059)$ & -0.070 & $-0.251^{a}$ & $(0.057)$ \\
\hline PP & $0.100^{b}$ & $(0.047)$ & 0.019 & $-0.168^{a}$ & $(0.044)$ \\
\hline PN & $-0.089^{b}$ & $(0.042)$ & -0.018 & $-0.265^{a}$ & $(0.042)$ \\
\hline$F$ & -0.017 & $(0.047)$ & -0.003 & $-0.279^{b}$ & $(0.044)$ \\
\hline NN & $-0.036^{a}$ & $(0.048)$ & -0.007 & $0.138^{a}$ & $(0.047)$ \\
\hline PS & -0.360 & $(0.050)$ & -0.083 & $-0.480^{a}$ & $(0.053)$ \\
\hline $\mathrm{NHI}$ (post 1995) & $-0.094^{c}$ & $(0.051)$ & -0.018 & $-0.311^{a}$ & $(0.051)$ \\
\hline Household income $(00,000)$ & $0.170^{a}$ & $(0.005)$ & 0.033 & $0.646^{a}$ & $(0.012)$ \\
\hline Household head -- male & 0.011 & $(0.016)$ & 0.002 & $0.083^{a}$ & $(0.018)$ \\
\hline Household head -- age & $-0.069^{a}$ & $(0.006)$ & -0.013 & $-0.160^{a}$ & $(0.007)$ \\
\hline Household head -- age $^{2}(00)$ & $0.074^{a}$ & $(0.007)$ & 0.014 & $0.171^{a}$ & $(0.007)$ \\
\hline \# of children under age 18 & $-0.144^{a}$ & $(0.020)$ & -0.028 & $-0.531^{a}$ & $(0.023)$ \\
\hline \# of children over age 18 & $-0.076^{a}$ & $(0.022)$ & -0.015 & $-0.535^{a}$ & $(0.036)$ \\
\hline Sample size & 64,967 & & & 64,967 & \\
\hline $\mathrm{R}^{2}$ & 0.123 & & & 0.667 & \\
\hline
\end{tabular}

Notes: Standard errors are in parentheses. Control variables also include constant, household head's 5 education dummies (junior, senior, community college, university, graduate school), spouse's 5 education dummies, region and year dummies which are not reported here.

${ }^{a}$ Statistically significant at the $1 \%$ level. ${ }^{b}$ Statistically significant at the $5 \%$ level.

${ }^{\mathrm{c}}$ Statistically significant at the $10 \%$ level. 


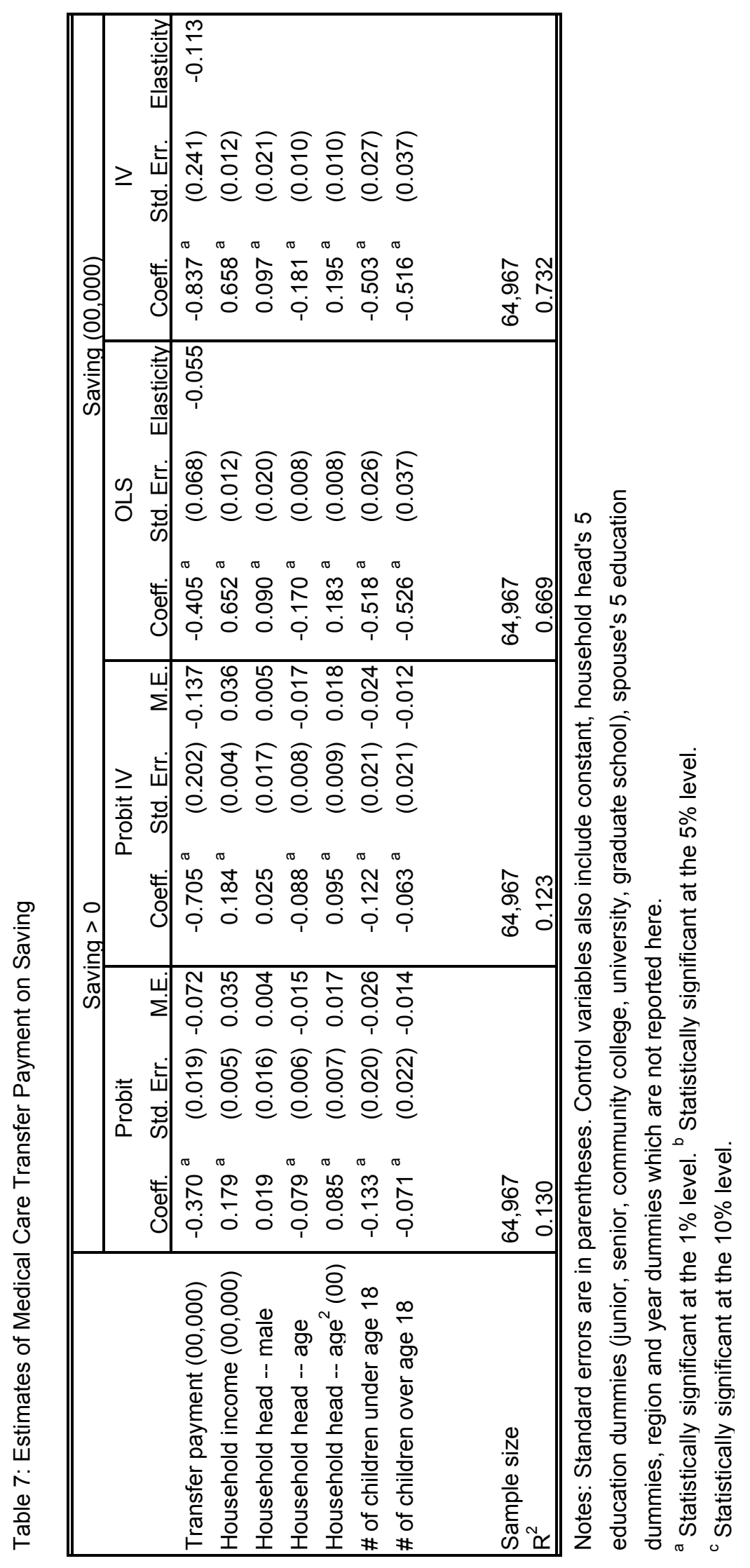




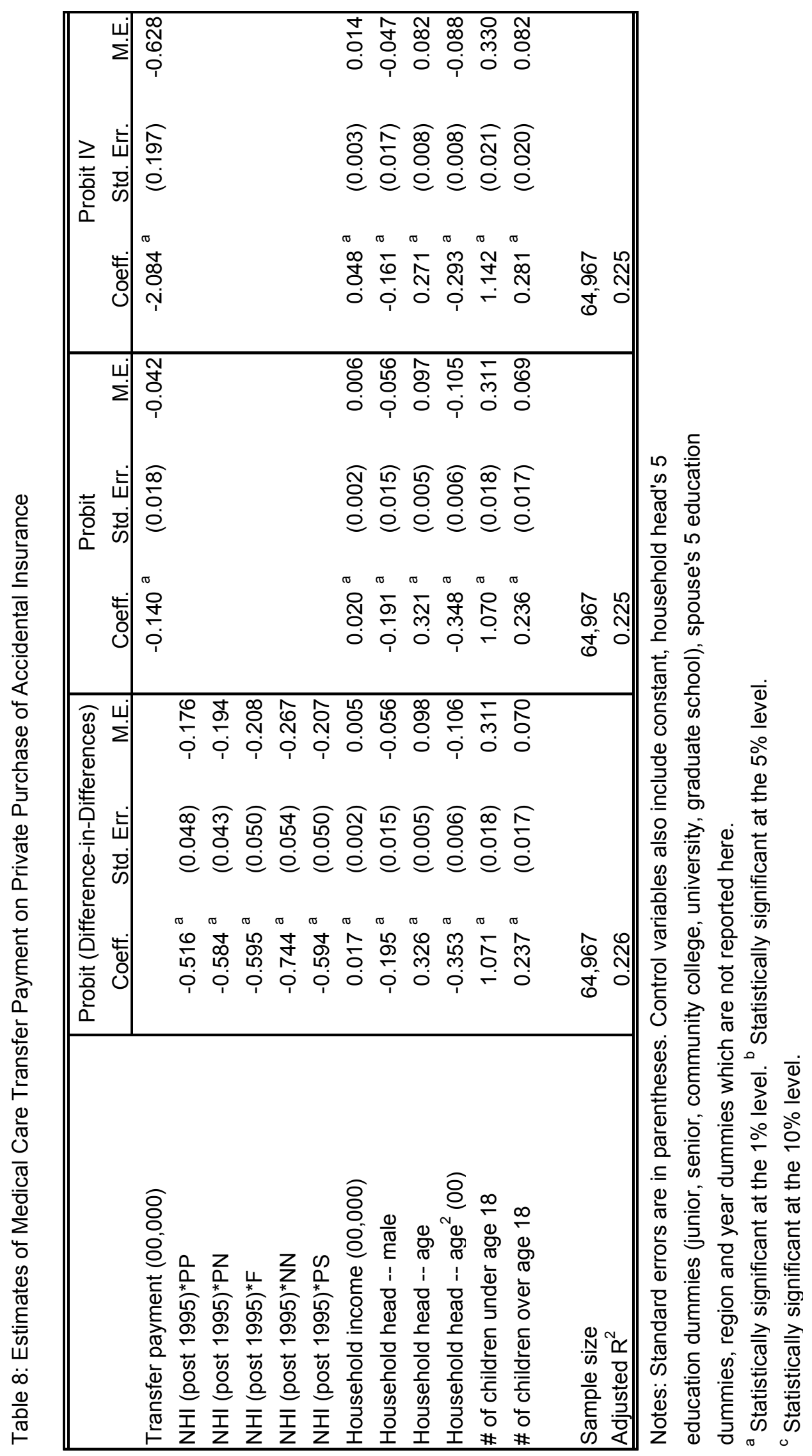




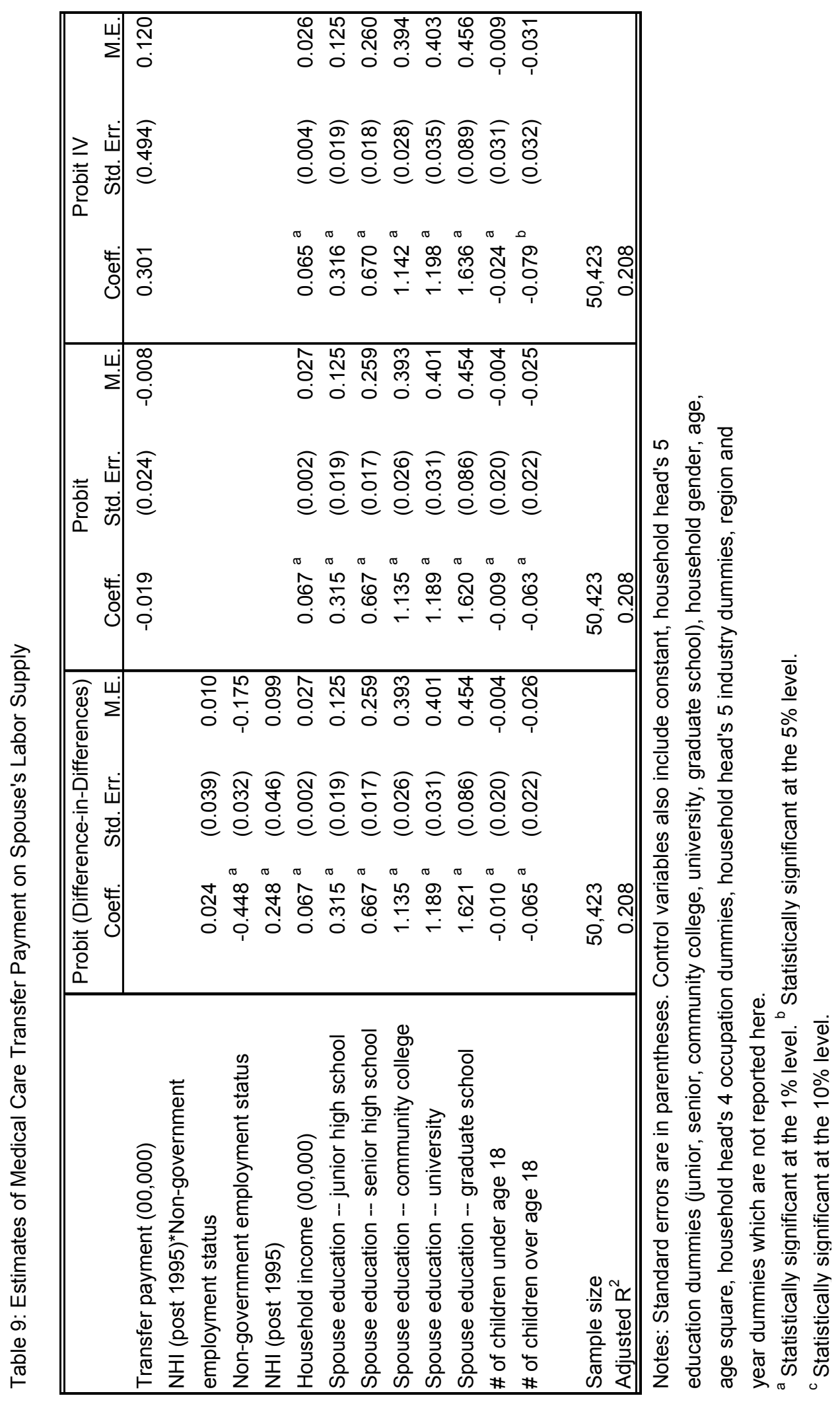




\section{References}

Angrist, Joshua D. and Alan B. Krueger. 2001. "Instrumental Variables and the Search for Identification: From Supply and Demand to Natural Experiments." Journal of Economic Perspectives 15: 69-87.

Bound, John, David A. Jaeger, and Regina M. Baker. 1995. "Problems with Instrumental Variables Estimation When the Correlation between the Instruments and the Endogenous Explanatory Variable is Weak." Journal of the American Statistical Association 90: 443-450.

Buchmueller, Thomas C. and Robert G. Valletta. 1999. "The Effect of Health Insurance on Married Female Labor Supply." Journal of Human Resources 34: 42-70.

Card, David. 1999. "The Casual Effect of Education on Earnings." In Orley Ashenfelter and David Card, eds., Handbook of Labor Economics. North Holland.

Carroll, Christopher D. and Andrew A. Samwick. 1998. "How Important is Precautionary Saving?" Review of Economics and Statistics 80: 410-419.

Cheng, Shou-Hsia and Tung-Liang Chiang. 1997. "The Effect of Universal Health Insurance on Health Care Utilization in Taiwan: Results from a Natural Experiment." Journal of American Medical Association 278: 89-93.

Chiang, Tung-Liang. 1997. "Taiwan's 1995 Health Care Reform." Health Policy 39: 225239.

Chou, Shin-Yi, Jin-Tan Liu, and James K. Hammitt. Forthcoming. "National Health Insurance and Precautionary Saving: Evidence from Taiwan." Journal of Public Economics.

Chou, Ying-Jeng and Douglas Staiger. 2001. "Health Insurance and Female Labor Supply in Taiwan." Journal of Health Economics 20: 187-211.

Cullen, Julie Berry and Jonathan Gruber. 2000. "Does Unemployment Insurance Crowd Out Spousal Labor Supply?" Journal of Labor Economics 18: 546-572.

Cutler, David and Jonathan Gruber. 1996. "Does Public Insurance Crowd Out Private Insurance?" Quarterly Journal of Economics 111: 391-430.

Deaton, Angus S. and Christina H. Paxson. 1994a. "Intertemporal Choice and Inequality." Journal of Political Economy 102: 437-467.

Deaton, Angus S. and Christina H. Paxson. 1994b. "Saving, Growth and Aging in Taiwan." In David A. Wise, ed., Studies in the Economics of Aging. Chicago and London: University of Chicago Press. 
Dynan, Karen E. 1993. "How Prudent Are Consumers?" Journal of Political Economy 101: 1104-1113.

Engen, Eric M. and Jonathan Gruber. 2001. "Unemployment Insurance and Precautionary Saving." Journal of Monetary Economics 47: 545-579.

Gertler, Paul and Jonathan Gruber. 2001. "Insuring Consumption Against Illness." American Economic Review 92: 51-70.

Gertler, Paul, Roland Sturm, and Bruce Davidson. 1994. "Information and the Demand for Supplemental Medicare Insurance." NBER Working Paper \#4700.

Gollier, Christian and John Pratt. 1964. "Risk Vulnerability and the Tempering Effect of Background Risk." Econometrica: 1109-1123.

Gruber, Jonathan. 1997. "The Consumption Smoothing Benefits of Unemployment Insurance." American Economic Review 87: 192-205.

Gruber, Jonathan and Brigitte C. Madrian. 2002 . "Health Insurance, Labor Supply and Job Mobility." NBER working paper \#8817.

Gruber, Jonathan and Aaron Yelowitz. 1999. "Public Health Insurance and Private Savings." Journal of Political Economy 107: 1249-1274.

Guiso, Luigi, Tullio Jappelli, and Daniele Terlizzese. 1992. "Earnings Uncertainty and Precautionary Saving." Journal of Monetary Economics 30: 307-337.

Hubbard, R. Glenn, Jonathan Skinner, and Stephen P. Zeldes. 1995. "Precautionary Saving and Social Insurance." Journal of Political Economy 103: 360-399.

Imbens, Guido and Joshua D. Angrist. 1994. "Identification and Estimation of Local Average Treatment Effects." Econometrica 62 : 467-475.

Kantor, Shawn Everett and Price V. Fishback. 1996. "Precautionary Saving, Insurance, and the Origins of Workers' Compensation." Journal of Political Economy 104: 419-442.

Kazarosian, Mark. 1997. "Precautionary Savings -- A Panel Study." Review of Economics and Statistics: 241-247.

Kimball, Miles S. 1993. "Standard Risk Aversion ." Econometrica 61: 589-611.

Kotlikoff, Laurence J. 1989. "Health Expenditures and Precautionary Savings." In Laurence J. Kotlikoff, ed., What Determines Savings. Cambridge, Massachusetts: MIT Press.

Meyer, Bruce D. 1995. "Natural and Quasi-Experiments in Economics." Journal of Business and Economic Statistics 13: 151-161. 
Olson, Craig A. 1998. "A Comparison of Parametric and Semiparametric Estimates of the Effect of Spousal Health Insurance Coverage on Weekly Hours Worked by Wives." Journal of Applied Econometrics 13: 543-565.

Peabody, John W., Joanna Chih-I Yu, Yi-Ren Wang, and Stephen R. Bickel. 1995. "Health System Reform in the Republic of China." Journal of American Medical Association 273: 777-781.

Pratt, John W. and Richard J. Zeckhauser. 1987. "Proper Risk Aversion." Econometrica 55: 143-154.

Skinner, Jonathan. 1988. "Risky Income, Life Cycle Consumption, and Precautionary Savings." Journal of Monetary Economics 22: 237-255.

Starr-McCluer, Martha. 1996. "Health Insurance and Precautionary Saving." American Economic Review 86: 285-295. 